\title{
A doutrina teleológica das ciências, o princípio metodológico da evidência e a Teleologia originária em Husserl
}

\author{
The teleological doctrine of the sciences, the \\ methodological principle of evidence and the \\ originating teleology in Husserl
}

CARLOS DIÓgENES C. TOURINHOa

\section{Resumo}

O presente artigo encontra-se dividido em três partes. Inicialmente, apresenta a doutrina teleológica das ciências na fenomenologia de Husserl. Em seguida, concentrase sobre o "princípio metodológico da evidência", de acordo com o qual as ciências não apenas querem formular juízos sobre objetos, mas fundá-los na evidência. Na terceira parte, o artigo aborda a "hierarquia das evidências", na qual notamos que toda evidência predicativa implica em uma evidência pré-predicativa. O exame desta última revela, por fim, uma teleologia originária da vida intencional.

Palavras-chaves: Edmund Husserl. Teleología. Ciencia. Evidencia. Intencionalidade.

\begin{abstract}
The present paper is divided into three parts. Initially, it presents the teleological doctrine of sciences in Husserl's phenomenology. It then focuses on the "methodological principle of evidence", according to which the sciences not only want to formulate judgments about objects but base them on the evidence. In the third part, the paper approaches the "hierarchy of evidence", in which we note that all predicative evidence implies in prepredicative evidence. The examination of the latter reveals, at last, an originating teleology from intentional life.
\end{abstract}

\footnotetext{
a Universidade Federal Fluminense (UFF), Niterói, RJ, Brasil. Doutor em Filosofia, e-mail: cdctourinho@yahoo.com.br
} 
Keywords: Edmund Husserl. Teleology. Science. Evidence. Intentionality.

\section{Introdução}

Um olhar panorâmico sobre o itinerário de Husserl no século XX permitenos notar, sobretudo, na década de 20, uma relação indissociável entre a doutrina teleológica das ciências e a teleologia da vida intencional. Se tal doutrina - segundo a qual as ciências almejam, continuamente, se constituir como "ciência autêntica" (echter Wissenschaft), tendo como fim o alcance de verdades "válidas para todos e de uma vez por todas" (ein für allemal und für jedermann gültig) — ganha, no mesmo itinerário, contornos mais nítidos no início da referida década, mais precisamente, em 1923/1924, no seminário de inverno, publicado em dois volumes sob o título de Filosofia Primeira, a estrutura teleológica da vida intencional recebe a sua primeira abordagem já na primeira edição de Investigações Lógicas (1900/1901), especificamente, no Capítulo 3 da Sexta Investigação, a propósito da distinção e das sínteses progressivas entre atos intencionais significativos e seus preenchimentos intuitivos. E é justamente o exame aprofundado desta distinção propedêutica para a qual Husserl retorna, insistentemente, ao longo de quase quatro décadas, chegando mesmo a considerá-la, em 1929, um "progresso decisivo da fenomenologia frente ao passado filosófico” (HUSSERL, [1929] 1981, p. 145) — que nos permite notar uma relação estreita entre a teleologia originária da vida intencional e o princípio metodológico da evidência. Afinal, Husserl jamais abdicou da tese - absorvida desde 1884, nos cursos de Brentano — segundo a qual toda consciência é "consciência de algo" (Bewußtseins von etwas). Esta tese irá, por sua vez, desdobrar-se, no itinerário husserliano, em uma dualidade fundamental que, ao se abrir, revela a distinção e síntese entre os atos intencionais significativos e seus preenchimentos intuitivos, assegurando-nos, assim, não apenas a "função simbólica" (symbolischen Funktion) de tais atos, mas também, graças à síntese em questão, a sua "função de conhecimento" (Erkenntnisfunktion). Se tais atos aspiram a uma realização intuitiva, os primeiros preenchimentos intuitivos aspirariam, ainda em uma esfera pré-predicativa e, portanto, própria da intuição sensível, a um preenchimento mais completo. Os referidos atos intencionais se inclinariam, cada 
A doutrina teleológica das ciências, o princípio metodológico da evidência e a Teleologia originária em Husserl

vez mais, através de experiências concordantes com seus respectivos preenchimentos, a um "ideal de preenchimento definitivo" (Ideal der letə̧ten Erfüllung), tendo como fim a "perfeição da adequação" (Vollkommenheit der Adäquation) entre o ato significativo e seu preenchimento intuitivo. Tal realização teleológica inerente à vida intencional da consciência somente se torna possível na medida em que a evidência - na condição de "primeiro princípio metódico" (erstes methodisches Prinzip) - assegura a presença da coisa (ou do estado da coisa) visada à consciência, garantindo-nos, segundo Husserl, a passagem do ato intencional enquanto um mero "presumir" a coisa visada para um ato no qual a coisa intentada encontrar-se-ia, em algum nível, presente "ela mesma" à consciência. A evidência (enquanto "doação das coisas elas mesmas") torna-se, assim, conforme Husserl esclarece-nos, nos $\iint 59$ e 60 de Lógica Formal e Lógica Transcendental (1929), responsável pela estrutura teleológica universal da consciência. Se a doutrina teleológica das ciências remetenos para a vida intencional da consciência, a exposição da primeira e a análise desta última revelam-nos o estreitamento da relação entre os conceitos de "teleologia" e de "evidência" na fenomenologia de Husserl. O presente artigo encontra-se dividido em três partes: a primeira delas aborda a "doutrina teleológica das ciências", apresentada, inicialmente, por Husserl em seu seminário de inverno de 1923/1924, intitulado Filosofia Primeira, e retomada nos primeiros parágrafos de Meditações Cartesianas, em 1931; já a segunda aborda o chamado "princípio metodológico da evidência", segundo o qual as ciências não apenas querem formular juízos sobre objetos, mas, fundá-los na evidência. Do contrário, elas próprias não poderiam avançar, ainda que parcialmente, nas suas realizações, em direção à pretensão de se constituir como uma "ciência autêntica". Para esta segunda parte, nos deteremos, especificamente, nos $\iint 59$ e 60 de Lógica Formal e Lógica Transcendental (1929); por fim, o presente artigo aborda, tomando a tarefa de refletir sobre os limites e alcance da evidência em questão, o que Husserl denomina de "hierarquia das evidências" (Stufenfolge der Evidenžen), mostrando que toda evidência predicativa implica em uma evidência pré-predicativa que, por sua vez, revela-nos uma teleologia originária da vida intencional. Para esta terceira parte, nos deteremos, especificamente, nos $\iint 84$ e 86 de Lógica Formal e Lógica Transcendental (1929), recorrendo, contudo, a um 
retorno às Investigações Lógicas (1900/1901), obra na qual Husserl apresenta-nos suas primeiras considerações sobre a relação entre teleologia e evidência, a propósito das experiências concordantes — de caráter "progressivo" e "teleológico" - entre atos intencionais significativos e seus preenchimentos intuitivos. O objetivo principal do presente artigo consiste, portanto, tomando como ponto de partida a exposição da doutrina teleológica das ciências, em destacar a importância do princípio metodológico de "somente julgar na evidência", debruçando-se, ao final, sobre a "hierarquia de evidências", por meio da qual somos conduzidos a uma evidência pré-predicativa na qual podemos notar uma teleologia originária da vida intencional na fenomenologia de Husserl.

\section{A doutrina teleológica das ciências}

Pode-se dizer que a chamada "doutrina teleológica das ciências" ganha, no itinerário husserliano, contornos mais nítidos no início dos anos 20, no seminário de inverno de 1923/1924, publicado, em dois volumes, sob o título de Filosofia Primeira (Erste Philosophie). Já na Lição 1 do Volume I, Husserl afirma-nos que as ciências são realizações produzidas por um trabalho teleológico. Cada ciência apresenta-nos, guardadas as suas especificidades, uma multiplicidade infinita de "produtos do espírito", mas o fazem sob a égide de uma ideia teleológica suprema — de um "arconte" (Archonten) — que lhes é comum, na medida em que impulsiona a própria atividade científica para as suas realizações. Neste sentido, Husserl afirmanos que as ciências teriam, para além de sua existência de fato, enquanto fenômeno de cultura, uma teleologia própria que as guiaria: a de pretender realizar, por um esforço contínuo, a ideia diretriz de se constituir como uma "ciência autêntica" (echter Wissenschaft). Trata-se de uma pretensão que tais ciências trariam consigo, sem que pudessem justificá-la através de sua própria existência enquanto fenômeno de cultura. E é justamente nesta pretensão para a qual Husserl nos chama a atenção que encontramos a ciência como ideia - “ideia de ciência autêntica" (Idee echter Wissenschaft). A atividade científica avança, por aproximações sucessivas, na obtenção do conhecimento. Todavia, se a ciência exerce, de tempos em tempos, a corrigibilidade de suas conjecturas, tal movimento converge, segundo Husserl, para aquilo que as ciências aspiram, em sentido verdadeiro e próprio, como um fim ideal: 
alcançar verdades "válidas para todos e de uma vez por todas" (ein für allemal und für jedermann gültig). Deste modo, afirma-nos o autor, a despeito de tal processo de corrigibilidade inerente à atividade científica, nada poderia impedir as ciências de viver, por um esforço contínuo, o sentido do que aspiram, preservando uma ideia clara e distinta do fim almejado. As ciências desenvolvem-se, então, em um "progresso infinito" (unendlichen Progressus), inclinadas à busca por maior exatidão e precisão, exibindo um estado corrente de realização, no qual tendem para o alcance de uma perfeição crescente, gradualmente realizada. Tal estado corrente de realização é, por conseguinte, algo "relativo" para a ciência, na medida em que os momentos alcançados tornam-se, enquanto realizações parciais, objetivos intermediários entre um estado que é menos e outro que é mais perfeito. Daí Husserl dizer, na Lição 29 do Volume II de Filosofia Primeira (Erst Pbilosophie), de 1924: no que concerne ao processo infinito de realização do movimento em direção ao conhecimento, "todo fim último é apenas um telos relativo" ("jedes Endžiel ist nur relatives $\left.\tau \dot{\lambda} \lambda o \varsigma^{\prime}\right)$ (HUSSERL, [1923/1924] 1959, p. 14). Muito embora tal estado de realização corrente seja imperfeito (uma vez que é transitório), ele exibe certa perfeição, ainda que relativa ao momento presente vivido pela ciência, preenchendo, com isso, nos termos da lição acima, certa "nostalgia" ("Sehnsucht"), mas preenchendo-a, através de atos de conhecimento, apenas de maneira relativa. Este momento é, de qualquer modo, um estado mais completo que aquele que the precedeu, de modo que a perfeição alcançada no momento seguinte seria como que o telos para o qual a ciência tendeu em seu estado anterior. Assim, cada estado corrente de perfeição não seria, para as ciências, um estado "definitivo" de perfeição. Aquele que está por vir representa para o estado presente um terminus para o qual ele tende e em relação ao qual ele é definido como um "ponto de partida". Assim, guiadas por esta "ideia diretriz" (Zweckidee) para a qual Husserl nos chama a atenção, as ciências creem superar completamente o conhecimento ingênuo, bem como superar in infinitum a si próprias, conforme vivenciam, progressivamente, esta intenção que, como uma tendência científica, se torna responsável por animar continuamente suas realizações parciais, guiando-as em sua tendência para a universalidade. A análise dos momentos constitutivos desta "ideia teleológica geral" 
(allgemeine Zweckidee) para a qual convergem as ciências remete-nos para o impulso de reviver o alcance do conhecimento que, para Husserl, consiste na liberdade de "realizar de novo" (Wieder-verwirklichung), de retornar, novamente, a uma justificação estabelecida ou verdade demonstrada como identicamente a mesma, fazendo dela própria uma aquisição. Tal impulso científico coloca-nos, por sua vez, diante daquilo que, aos olhos do autor, justificaria o sentido do conhecimento: a "evidência" (Evidenz, Einsicht), entendida como “doação das coisas elas mesmas”. Haveria, assim, para Husserl, uma relação estreita entre a doutrina teleológica das ciências e o "princípio metodológico da evidência”. Sem a possibilidade de fundar os juízos científicos na evidência, verificando-os naquilo que se evidencia, as ciências não poderiam avançar em direção à "ideia fim" que as determina teleologicamente. Afinal, o recurso à evidência é justamente o que permite, por um "retorno às coisas mesmas", confirmar ou não a adequação material (decidir pela verdade ou falsidade) de um juízo objetivo. Daí Husserl nos dizer, na Lição 2 do Volume I de Filosofia Primeira, que: "Um ato de julgamento verdadeiro é um ato de julgamento que se confirma necessariamente ou pode se confirmar na evidência" (HUSSERL, [1923/1924] 1956, p. 30). Neste sentido, tal princípio metodológico (de somente julgar na evidência) é, justamente, o que torna possível às ciências a realização sistemática da ideia teleológica em questão. Detenhamo-nos, então, em torno da referida relação.

\section{O princípio metodológico da evidência}

Em sentido mais amplo, a evidência nos proporciona, segundo Husserl, a experiência de um ser e da sua maneira de ser. Nela, a coisa intencionada não é apenas visada de forma distante ou "remota" (sachfernen), como objeto de uma intenção meramente significativa. Antes disso, a coisa visada nos é, de certo modo, presente "ela própria”, em seu estado de coisa "ele próprio". Daí Husserl dizer, no \59 de Lógica Formal e Lógica Transcendental (1929), que a evidência significa a "realização intencional de autodoação" (intentionale Leistung der Selbstgebung), consistindo, por excelência, na "forma geral" (allgemeine Gestalt) da intencionalidade (HUSSERL, [1929] 1981, p. 141). O autor afirma-nos, no \60, que a doação das coisas elas mesmas é como uma "função" (Funktion) no conjunto universal da 
consciência, havendo, segundo ele, uma relação de "parentesco" (zusammengebörige) entre os conceitos de "intencionalidade" e de "evidência" (HUSSERL, [1929] 1981, p. 143). Tudo isso faz com que Husserl considere a evidência como um "primeiro princípio metódico" (erstes methodisches Prinzip), destinando-o a reger, na investigação de um objeto, todos os passos ulteriores. Como lembra o autor, ao asserir predicações sobre os objetos, a ciência não quer apenas formular, de maneira geral, juízos acerca dos mesmos, mas fundá-los ou verificá-los (à tout moment) na evidência, não podendo atribuir validade final a um juízo qualquer (nem tampouco atribuir ao juízo o valor de uma etapa intermediária no caminho que conduzisse à validade final) se não tiver extraído tal validade judicativa do que é evidente. Do contrário, a própria ciência não avançaria, conforme vimos, na realização — ainda que parcial — da "ideia diretriz" (Zweckidee) que a guia em direção à universalidade.

O ato de julgar é, antes de tudo, uma intenção e, em geral, uma simples "presunção" (Vermeinen) de que uma coisa seja isso ou aquilo. Neste caso, o que é afirmado pelo juízo é apenas coisa ou estado de coisa presumido, visado pelo pensamento e, portanto, "estado de coisa pensado" (Denksachverhalt). Em geral, para Husserl, enunciar proposições judicativas, por mais viva que seja a convicção em tal enunciação, não é ainda "conhecer", no sentido autêntico da palavra. Tal intenção puramente presuntiva deve, inicialmente, demonstrar o seu valor de verdade, algo que somente se torna possível pela adequação da intenção inicial a uma intuição correspondente, ao localizar diante do olhar, a coisa "ela mesma" (o seu estado "ele próprio"), revelando-a, nos termos de Husserl, "em pessoa". Trata-se, em resumo, de tornar um mero visar em um estado de coisa, em uma intenção "fundada" ("begründet"), no sentido de "elevá-la à evidência" ("einsichtig gemacht"). Com isso, eventualmente, deparamo-nos com outro julgar intencional, no qual temos, de certo modo, a presença à consciência do que é julgado, ou como gosta de dizer Husserl: a "efetiva doação das coisas" (die wirkliche Selbstgebung der Sachenreicht) (HUSSERL, [1931] 1973, p. 54). Tal conversão de um mero julgar presuntivo em um julgar intencional no qual a coisa julgada se faz, de certo modo, presente à consciência torna-se assegurada pela evidência da coisa "visada e autodada" (Gemeinte und Selbstgegebene). Dá-se uma conformação entre o ato de visar e seu preenchimento 
intuitivo, fazendo com que o julgamento meramente presuntivo torne-se objetivamente verdadeiro, na medida em que o mesmo se confirma na evidência. Nos termos do \51 de Prolegômenos, Husserl descreve-nos tal confirmação como: "A vivência da consonância entre o visado e o que está presente em si mesmo [...]" ("Das Erlebnis der Zusammenstimmung zwischen der Meinung und dem selbst Gegenwärtigen...”) (HUSSERL, E. [1900] 1913, \ 51, p. 190).

A exigência metodológica segundo a qual o cientista deve fundar na evidência os juízos que formula será, segundo Husserl, sucedida por outra: a de refletir sobre o alcance e limite da própria evidência em questão, explicitando o grau de perfeição no qual uma coisa qualquer nos é efetivamente dada. Afinal, a perfeição ideal exigida pela evidência diferencia-se, podendo ser, nos termos do autor, "mais ou menos perfeita" (mehr oder minder vollkommener). Temos perante nós uma infinidade de experiências ou evidências pré-científicas. Daí Husserl nos dizer, no \60 de Lógica Formal e Lógica Transcendental, que toda consciência de alguma coisa faz parte a priori de uma "multiplicidade ilimitada de modos possíveis de consciência" (endlose Mannigfaltigkeit möglicher Bewußtseinsweisen), tais como, os modos de percepção, recordação, imaginação, etc., que podem ser religados enquanto consciência da “mesma coisa". À multiplicidade em questão pertencem, igualmente, por essência, os distintos modos de uma "consciência de evidência" (Evidenz̧bewußtseins) que se inserem nesta multiplicidade segundo a maneira que convém a cada caso: na percepção, a doação da coisa ela mesma em um "agora atual”; na recordação, a reprodução de um "ex-agora"; na imaginação, a experiência neutralizada do "como se" (als ob), e assim por diante. Portanto, a designação válida para "todas" as modalidades de consciência, segundo a qual a evidência implicaria na "doação de um objeto ele mesmo (ou para falar do lado do sujeito: na posse de um objeto ele mesmo)" (HUSSERL, [1929] 1981, p. 144), não deve impedir-nos de notar que a estrutura da evidência não se mostra semelhante em todos os casos, uma vez que haveria, para cada modalidade de consciência, nos termos de Husserl, um "estilo de evidência" (Evidenștiles). Daí o autor nos dizer, ainda no $\int 60$ da referida obra, que “para toda espécie fundamental de unidades da 'experiência' possível, convém uma espécie fundamental da 'experiência' da evidência” (HUSSERL, [1929] 1981, p. 144). O exame de tais modalidades de consciência revela-nos, na fenomenologia de 
Husserl, a percepção como o vivido intencional paradigmático em relação aos demais (recordação, imaginação, judicativo, etc.), assim como uma teleologia originária que lhe é própria. Tudo isso implicará em uma hierarquia de evidências entre o que é "predicativo" e "pré-predicativo". Vejamos.

\section{A hierarquia das evidências e a teleologia originária}

Referindo-se a esta "nova tarefa", segundo a qual devemos refletir sobre o alcance e limites da evidência, Husserl afirma-nos que toda "evidência predicativa implica em uma evidência pré-predicativa" (Prädikative Evidenz schließt vorprädikative ein) (HUSSERL, [1931] 1973, \ 4, p. 52). Quer dizer, implica, em última instância, caso façamos uma gênese do sentido dos juízos, em qualquer coisa visada, respectivamente, vista evidentemente (na esfera sensível) e expressa na esfera predicativa (primeiramente, nos "juízos de experiência”). Tal afirmação remete-nos para o que Husserl denomina, no \ 84 de Lógica Formal e Lógica Transcendental (1929), de "hierarquia de evidências" (Stufenfolge der Evidenzenn). O autor nos diz, no mesmo parágrafo, que a hierarquia dos julgamentos e de seus sentidos corresponde à hierarquia das evidências, de modo que "as verdades e as evidências primeiras em si devem ser as verdades e as evidências individuais” (HUSSERL, [1929] 1981, p. 182). Quando seguimos o fio condutor da gênese do sentido, recuando até o seu nível mais baixo, deparamo-nos com "juízos sobre indivíduos” (Individualurteile), por meio dos quais temos a evidência de estados de coisas individuais. Neste sentido, nesta hierarquia, os juízos cuja evidência é, efetivamente, a mais originária devem ser $a$ priori os "juízos de experiência” (Erfahrungsurteile), dirigidos sobre os dados da percepção. Trata-se de juízos sobre indivíduos que, por sua vez, nos são revelados diretamente pela experiência, aqui concebida, no sentido "primeiro" (ersten) e "mais forte" (prägnantesten), como "referência direta ao indivíduo" (als direkte Beziebung auf Individuelles) (HUSSERL, [1929] 1981, p. 183). Daí Husserl mencionar, em destaque, no $\int 86$ da referida obra de 1929, a proposição — extraída da doutrina geral da consciência e, mais precisamente, da fenomenologia da gênese universal da consciência - segundo a qual a consciência do modo de doação dos objetos eles mesmos, em uma atualidade e, portanto, no vivido intencional de percepção, 
"precede" todos os outros modos de consciência, sendo estes últimos (recordação, imaginação, judicativo, etc.) "geneticamente secundários" (genetish sekundären). Eis, portanto, em Husserl, o primado da experiência perceptiva (como referência direta aos indivíduos) em relação aos demais modos de consciência. Tal primado leva o autor a afirmar: "o que é primeiro em si em uma teoria dos julgamentos evidentes é o retorno genético das evidências predicativas à evidência não predicativa que se chama então experiência" (HUSSERL, [1929] 1981, p. 186). Esta última evidência entra no julgar que se encontra no nível o mais baixo do ponto de vista genético. Encontramo-nos frente ao começo primeiro em si de uma teoria sistemática do julgamento. Localizando-nos neste começo é que podemos descobrir que a distinção entre intenção presumida e seu preenchimento não pertence exclusivamente à esfera predicativa, mas, supõe, no retorno predicativo da gênese do sentido, a experiência pré-predicativa. Neste sentido, no mesmo $\int 86$, Husserl confirma que "a intencionalidade dos julgamentos predicativos levam-nos, no final das contas, à intencionalidade da experiência" (HUSSERL, [1929] 1981, p. 186), de modo que a evidência primeira em si torna-se aquela da experiência.

As ciências aspiram predicações destinadas a dar à intuição pré-predicativa uma expressão completa e evidentemente adequada. E é justamente o princípio metódico de "somente julgar na evidência" (nur in Evidenz. zu urteilen) que deverá reger esta tarefa. A evidência pré-predicativa supõe, por sua vez, no plano sensível, uma coisa visada, cuja presença à consciência atesta-nos a sua evidenciação. Em termos husserlianos, através da evidência da coisa visada, a intenção vazia preenchese: tem-se um "preenchimento de significação" (Bedeutungserfüllung). Passamos de uma mera presunção do ato que intenciona a coisa visada para a presença intuitiva da coisa "ela mesma" à consciência. Deparamo-nos, em tal passagem, com uma camada teleológica mais originária. Husserl chama-nos a atenção, no caso da percepção, para os graus sucessivos de preenchimento intuitivo dos atos intencionais, nos quais a evidência diferencia-se, assegurando o aclaramento gradativo do objeto visado. No Capítulo 3 da Sexta Investigação de Investigações Lógicas, Husserl salienta que, em cada preenchimento de atos significativos, encontramos um "tornar-se intuitivo" que, por sua vez, é mais ou menos completo. Husserl mostra-nos, especificamente, no caso da percepção de um objeto, que tal 
preenchimento impõe-nos gradações, algo da ordem de uma relação de aumento, uma vez que, ao atribuir "plenitude" ("Fülle") ao ato, este tornar-se intuitivo assegura a presença daquilo que é visado pelo ato significativo, mas esta presença se faz, gradativamente, em uma série de preenchimentos que aumentam progressivamente o conhecimento do objeto, em termos de vivacidade ou riqueza do que é intencionado, confirmando, com isso, em níveis crescentes, a realização (ou atualização consciente) da referência objetiva. Se tais atos intencionais significativos aspiram a um preenchimento intuitivo, cada grau de preenchimento aspiraria, por sua vez, a um "ideal de preenchimento definitivo" (Ideal der letzten Erfüllung), tendo como fim a "perfeição da adequação" (Vollkemmenheit der Adäquation) entre o ato intencional significativo e seu preenchimento intuitivo. $\mathrm{O}$ aperfeiçoamento opera-se, então, numa "progressão sintética" (synthetischer Fortgang) de experiências concordantes, em que essas intenções significantes se elevam ao estádio de experiência efetiva que as confirma e as preenche. Nos termos da Lição 28 do Capítulo 1 de Filosofia Primeira (Volume II), o objetivo a ser alcançado é inicialmente presumido (vermeinten), depois realizado em uma obtenção imperfeita (unvollkommenen Erzielung) e, por fim, efetivamente perfeita (wirklich vollkommene) (HUSSERL, [1923/1924] 1959, p. 9). Em tal série de preenchimentos com implicações progressivas, tratar-se-ia, portanto, de uma camada teleológica inerente à vida intencional. Neste sentido, poder-se-ia dizer que "intencionalidade é teleologia" (MURALT, 1974, p. 27). Tal realização teleológica na progressão sintética das experiências concordantes entre os atos intencionais significativos e seus preenchimentos intuitivos somente acontece na medida em que a evidência daquilo que é visado por tais atos assegura a sucessão dos preenchimentos intuitivos, ainda em uma esfera pré-predicativa e, portanto, sensível. Daí Husserl nos dizer, no $\int 60$ de Lógica Formal e Lógica Transcendental, a propósito da relação entre teleologia e evidência que: "a evidência é um modo da intencionalidade universal relacionada à vida inteira da consciência; graças a ela, a vida da consciência tem uma estrutura teleológica universal" (HUSSERL, [1929] 1981, p. 143). Sendo assim, todos os momentos de realização do desenvolvimento da ciência se encontrariam, para Husserl, envolvidos com uma teleologia intencional originária 
que, por sua vez, somente se realizaria graças à "evidência" das coisas visadas à consciência.

\section{Conclusão}

Um olhar panorâmico sobre o itinerário husserliano, mais precisamente, sobre os textos da década de 20, permite-nos notar, conforme mostramos, a relação indissociável entre a "doutrina teleológica das ciências" — segundo a qual as ciências seriam guiadas teleologicamente pela "ideia fim" de se constituir, para além de sua existência enquanto fenômeno de cultura, como uma "ciência autêntica", aspirando alcançar verdades "válidas para todos e de uma vez por todas" - e a teleologia originária da vida intencional da consciência. Ainda que a referida ideia se realize parcialmente, as ciências não deixam, contudo, de vivê-la, continuamente, enquanto um fim a ser alcançado. Trata-se, portanto, de uma "forma teleológica superior" (böherer Zweckeform) que religa as ciências a um mesmo telos, a despeito da especificidade de cada domínio científico. Tal forma encontra-se diretamente conectada a outra, de ordem "inferior" (niederer), na qual encontramos, nos diferentes domínios da ciência, a realização da produção científica. E é justamente nesta realização que somos remetidos para a vida intencional da consciência. Afinal, toda vivência cognoscitiva é, antes de tudo, vivência de alguma coisa. O cientista não quer, conforme vimos, apenas formular juízos sobre os objetos que investiga, mas também - e, sobretudo — fundar tais juízos na evidência, uma vez que a formulação de juízos nas ciências por si só não asseguraria conhecimento algum caso não pudéssemos retornar, novamente, pelo testemunho daquilo que se evidencia, a uma justificação estabelecida ou verdade demonstrada como identicamente a mesma, fazendo dela própria uma aquisição. Eis, para Husserl, um primeiro princípio metodológico: "somente julgar na evidência". Se em sentido stricto a questão do método remete-nos, na fenomenologia, para o exercício da redução fenomenológica (com as etapas que lhe são próprias), o sentido propedêutico desta questão torna claro que o caminho por meio do qual somos conduzidos ao conhecimento é o da intuição e, portanto, da evidência. Mas, se a exigência de somente julgar na evidência assume, por excelência, o lugar de "princípio metodológico", a aceitação de tal exigência coloca-nos, conforme o artigo 
mostrou, frente a uma nova tarefa: a de refletir sobre o alcance e limite da referida evidência. Tal reflexão deixa-nos, por sua vez, frente a uma correlação entre as diferentes modalidades de vivido intencional (percepção, recordação, imaginação, judicativo, etc.) e modalidades de evidência. Neste ponto, Husserl é categórico ao apontar a primazia do vivido de percepção sobre os demais. Somo, então, remetidos para uma "hierarquia de evidências". Daí Husserl dizer, a propósito da reflexão sobre o limite e alcance das evidências, que toda evidência "predicativa" implica em uma evidência "pré-predicativa". No retorno predicativo da gênese do sentido, se caminhamos "para trás", encontraremos os primeiros juízos que, para Husserl, são “juízos de experiência” e, portanto, sobre indivíduos. São, com isso, juízos que implicam em evidências pré-predicativas. Encontramo-nos, assim, face à experiência. E é justamente neste exame do que é pré-predicativo, que encontramos uma teleologia originária imanente à vida intencional. Os primeiros preenchimentos intuitivos aspiram, já na esfera da intuição sensível, a preenchimentos ainda maiores, tendo como fim, ao longo de uma síntese progressiva de experiências concordantes, um ideal de "perfeição de adequação". Tal realização teleológica somente se torna possível pelos sucessivos preenchimentos intuitivos dos atos intencionais, revelando-nos, assim, uma aproximação estreita entre a teleologia originária da vida intencional e a evidência das coisas visadas à consciência. A evidência torna-se, assim, na fenomenologia de Husserl, a principal responsável pela estrutura teleológica universal da consciência, manifestando uma relação de parentesco com o próprio conceito de intencionalidade, cuja formulação não pôde deixar de influenciar decisivamente os principais momentos do itinerário husserliano.

\section{Referências}

HUSSERL, E. Logische Untersuchungen. Erster Band. "Prolegomena zur reinen Logik". Halle a. d. S.: Max Niemeyer, ([1900] 1913a).

HUSSERL, E. Logische Untersuchungen. Zweiter Band. Teil I. "Untersuchungen zur Phänomenologie und Theorie der Erkenntnis". Stuttgart, Tübingen: Max Niemeyer Verlag, ([1901] 1913b, 1968). 
HUSSERL, E. Logische Untersuchungen. Zweiter Band. Teil II. "Elemente einer phänomenologischen Aufklärung der Erkenntnis”. Stuttgart, Tübingen: Max Niemeyer Verlag, ([1901] 1913c, 1968).

HUSSERL, E. Erste Philosophie (1923/1924). Erster Teil. The Netherlands: Martinus Nijhoff, ([1923/1924] 1956).

HUSSERL, E. Erste Philosopbie (1923/1924). Zweiter Teil. The Netherlands: Martinus Nijhoff, ([1923/1924] 1959).

HUSSERL, E. Formale und transzendentale Logik. Versuch einer Kritik der logischen Vernunft. Tübingen: Max Niemeyer Verlag, ([1929] 1981).

HUSSERL, E. Cartesianische Meditationen und Pariser Vorträge. Husserliana (Band I). Den Haag, Netherlands: Martinuos Nijhoff, ([1931/ 1929] 1973).

MURALT, A. The Idea of Phenomenology: Husserlian Exemplarism. Evanston: Northwestern University Press, 1974.

RECEBIDO: $18 / 04 / 2019$

RECEIVED: 04/18/2019

APROVADO: $27 / 06 / 2019$

APPROVED:06/27/2019 